It is difficult to put forward any simple explanation for the growth mechanism. The zinc sulphide used in this experiment was luminescent grade zinc sulphide pre-firod at $700^{\circ} \mathrm{C}$. in a stream of hydrogen sulphide to eliminate any trace of zinc oxide and sulphur. The same luminescent grade zinc sulphide, non-prefired, yielded, in the same operating conditions, beautiful hexagonal needles many millimetres long.

I wish to thank Dr. M. H. Aven of this laboratory for supplying me with the rinc sulphide powder purified in hydrogen sulphide.

Arrigo Andamino

\author{
Lamp Research Laboratory, \\ Lamp Division, \\ Goneral Electric Company, \\ Nela Park, \\ Cleveland, Ohio. \\ Dec. 5 . \\ 'Nature, 173, 38 (1954) (cf. Hig. 1).
}

\section{A Method of measuring the Adhesion of Organic Coatings to Metals}

WE have recently devised a method for measuring the adhesion of organic coatings to metal surfaces, which, unlike many others ${ }^{1.2}$, enables the adhesion to be distinguished from the mechanical properties of the coatings and also, since it does not need to be operated in a vacuum as do some methods ${ }^{3,4}$, may be used to study the effects of various atmospheric and other conditions on adhesion.

The method consists of decelerating coated metal from a high velocity in such a way as to apply a force to the coating which causes it to fly off the metal surface. A 'bullet' in the form of a thin steel disk, punched from a panel coated with the substance under test, and with an annulus of coating removed so as to leave a spot of coating in the centre, is fired from an air gun at a hard steel target having a hole in line with the coated spot of the 'bullet'. 'The 'bullet' is kept straight in the gun by a brass sleeve. The coating is decelerated by the force generated when the 'bullet' is stopped, and, if the force is high enough, becomes detached by its own momentum. By firing 'bullets' at different velocities, the threshold velocity at which the coating becomes detached can be determined. The force is highest at the interface with the substrate, an advantage which the method shares with those of Malloy, Soller and Roberts ${ }^{3}$ and of Moses and Witt.

It has so far not been possible, because of the complex deformations that occur, to calculate the deceleration of the 'bullet' from incident velocity. It has therefore been determined experimentally by measuring the change in capacitance due to the approach of the 'bullet' to a probe inserted into the hole of the target, and the results agree fairly well with such theoretical predictions as have been made. The maximum deceleration obtainable is about $3 \times 10^{7} \mathrm{~g}$, which yields a force of $1.5 \times 10^{8} \mathrm{dynes} / \mathrm{cm} .^{2}$ for a coating $5 \times 10^{-3} \mathrm{~cm}$. thick and a density of $1.0 \mathrm{gm}$. $/$ c.c. This force is sufficient for the measure. ment of the adhesion of good paints, and we have obtained results between $5 \times 10^{7}$ dynes $/ \mathrm{cm}^{2}$ and $10^{9}$ dynes $/ \mathrm{cm}^{2}$, similar to those reported by Malloy, soller and Roberts ${ }^{3}$.

The measurement is repeatable to about \pm 10 per cent, and the mothod has shown an agreement of \pm 12 per cent with direct tensile measurements of the adhesion of coatings which were amenable to both methods. A more detailed account of the method will be published elsewhere.

W. D. May

N. D. P. Sмптн

C. I. SNow

I.C.I. Paints IDivision, Wexham Road, Slough, Bucks. Dec. 4.

${ }^{1}$ Rolle, C. J., and Dietrich, T. L., Anal. Chem., 21 (1949).

2 Rossman, E., Fédération d'Association de Techniciens des Industries des Peintures, Vernis, Emaux et Encres d'Imprimerie de l'Europe Continentale Congress, 1953.

${ }^{3}$ Malloy, A. M., Soller, W., and Roberts, A. G., Paint, Oil and Chem. Rev., 116 (18) (1953).

- Moses, S., and Witt, R. K., Indust. Eng. Chem., 41, No. 10 (1949).

\section{Colour Photomicrography of Colourless Objects}

Coloured photomicrographs of yeast cells have been produced without special apparatus (such as an interference microscope).

Since the internal structure of yeast cells is usually changed by fixation and staining, living cells were used, and some quite pleasing results were obtained when cells from a malt-grown culture were vitalstained with strong aqueous janus green and photographed in yellow light (Wratten No. 15 filter).

Next, an attempt was made to use Rheinberg illumination ${ }^{1}$. This is a modified form of dark-ground illumination in which the sub-stage condenser stop is replaced by a transparent darkly coloured disk, and the surrounding annulus is filled by a second filter of paler but contrasting colour. Objects viewed through the microscope under low powers reflect the colour of the annulus, while the background takes the colour of the stop; but with increasing powers of objectives, the system becomes increasingly difficult to set up, and it will not operate with $2 \mathrm{~mm}$. objectives.

However, a modification was discovered which can be used only-and very effectively--with $4 \mathrm{~mm}$. and $2 \mathrm{~mm}$. objectives. Two filters of contrasting colours were placed side by side with their adjacent edges in contact, in the beam of parallel light which enters the substage condenser of the microscope. When the condenser had been focused for critical illumination, the filters were arranged so that the two colours filled exact halves of the low-power field. Under these conditions, an effect similar to Rheinberg illumination was obtained by the overlap of the two colours, when an object was viewed under high power. A variety of effects could be obtained by making small lateral movements of the filters, and these ranged from one background colour with contrasting cells to the opposite colour combination.

The method has been used successfully for photomicrography of yeast cells, when red (Wratten No. 25) and green (Wratten No. 58) filters were used, and it should be applicable to any colourloss objects of less than about $50 \mu$ in diameter.

$$
\text { J. D. Lavi }
$$

Research and Development Department,

Distillers Company, Ltd., Great Burgh,

Epsom, Surrey. Dec. 4.

${ }^{1}$ Olliver, C. W., "The Intelligent Use of the Microscope", 89 (Chapman and IIall, 'London, 1947). 